\title{
Exploratory Study on Learning Organization: A Case Study in Faculty of Economics of a Private University in Jakarta, Indonesia
}

\author{
Nita Handastya, , \\ Atma Jaya Catholic University of Indonesia - Faculty of \\ Economics \\ 12930, DKI Jakarta - Indonesia
}

Levi Nilawati

Atma Jaya Catholic University of Indonesia - Faculty of Economics

12930, DKI Jakarta Ï Indonesia

\author{
Andy Susilo Lukito Budi \\ Atma Jaya Catholic University of Indonesia - Faculty of \\ Economics \\ 12930, DKI Jakarta Ï Indonesia
}

\begin{abstract}
University is a center of knowledge that produces both ideas and thinkers. However, can such an institution be automatically called learning organization? Learning is, according to Senge (1990), the only means of survival in this changing world. In a hierarchical organization such as a faculty, many things interfere with the learning process, just as other types of organization. The reason Faculty of Economics was chosen for this study was the fact that it is the oldest and largest faculty in the university it belongs to. This paper attempts to study whether or not the Faculty of Economics is a learning organization based on Senge's five disciplines. This paper used both qualitative and quantitative approaches to explain the learning organization in the context of educational institution. The method of data collection was through surveys and in-depth interviews. The questionnaire was based on Neefe's (2001) and the interview was based on Senge's (1990). The respondents were both academic and administrative employees of the faculty, to provide a broader view. According to the quantitative approach, most respondents agreed that the faculty of Economics is a learning organization. However, the qualitative approach resulted in a fairly different conclusion. While the first approach shows the concept of learning organization, the latter shows that things are not as they seem since there are forces that drive the system in an invisible way. Indeed, both approaches complement one another, providing a wholesome image of the faculty. This research was started with the quantitative approach, and then complemented by the qualitative approach. The findings also show that system thinking is the most fundamental discipline but it is still greatly affected by the mental models of the faculty members.
\end{abstract}

Keywords: Learning Organization; Learning in University; Organizational Culture Introduction

\section{INTRODUCTION}

In the $21^{\text {st }}$ century, every aspect of humanity has been developing rapidly, leading to many changes in various aspects. This fact affects every organization and individual in the process of the change itself. Change is something that can contribute toward progress, but it is also a threat that may lead one to failure. Universities as a form of organization are not immune to this fact. A number of universities in Indonesia alone have been declared bankrupt due to their inability to sustain themselves. Many factors affecting these, among others, are: their inability to meet the standards imposed by the government, inability to compete in a highly competitive higher education industry, and failure to attract new students as a source of funding. As an independent organization that has to generate profit to survive, a university, especially that of private owned, has to discover its own competitive advantage and amplify it in order to survive and stay in the competition.

Atma Jaya Catholic University of Indonesia (THE UNIVERSITY) is one of the major private universities in Jakarta, Indonesia. It is shown by its achievement in the past and how the survey shows public trust toward the institution. At its maturity age, THE UNIVERSITY as one of the major universities in Indonesia has been through many obstacles and stays competitive. Yet, surviving today does not mean surviving tomorrow. THE UNIVERSITY still faces threats imposed by changes. In THE UNIVERSITY, the Faculty of Economics is the oldest and largest faculty, which reflects the university in term of age and size. As said by Marquardt (2002), old and big organizations tend to be like dinosaurs: slow and rigid, fragile toward changes.

According to Senge (1990), learning is the only means of survival in the changing world, while de Geus (1988) stated that the ability to learn faster than your competitors might be the only sustainable competitive advantage. According to Kapp (1999), a learning organization is a group of people who have woven a continuous, enhanced capacity to learn in the corporate culture, an organization in which learning processes are analyzed, monitored, developed, and aligned with competitive goals. A learning organization generates knowledge and learning faster than competitors do and turns that learning into a strategic advantage to outmarket, outmanage, and outsell competition. This is why it is very important for an organization to be learning, especially an organization that was intended to generate ideas and innovation. In this way, this study attempts to explore learning in one of the major universities in Indonesia. 


\section{THEORETICAL BACKGROUND}

Learning is very important in university. This process also includes the process of finding mistakes and a chance of recovering and reformation (Argyris and Schon, 1996). Neefe in her 2001 study compared six literatures and found a common theme among the six literatures (Senge, ASTD; Bennet\&Oôrien; Gephart\&Marsick; Goh, Kaplan \& Norton; and Gavin) to describe learning organization in university. She found that from fifteen characteristics proposed by the six literatures (Personal Mastery, Mental Models/Culture/Climate, Shared Vision/Mission, Team Learning, Training, System Thinking, Leadership, Management/Executive Practices, Communication Systems, Information, Knowledge, Structure, Change Facilitation, Work Processes, Rewards \& Recognition, and also Performance Management), there are six elements that emerge consistently in most of the literatures, which are: Leadership, Shared Mission/Vision, Teamwork and Team Learning, Organizational Culture, System thinking, and Employee Skills \& Capabilities. While Neefe compared 6 literatures to find this theme, she also included Sengeôs five disciplines in her source. The researcher found that Neefe and Senge share a unique perspective. While Senge spoke of organization of any type in general, Neefe focused the topic only on the universities. Inspecting Sengeôs five disciplines, Senge used a different term for each discipline, namely: Personal Mastery (Employee Skills and Capabilities), Team Learning (Team work and learning), Mental Models (Organizational Culture), while the Shared Vision and System Thinking are still the same. One element that is missing in Senge and found in Neefe is Leadership. Neefeôs research shows that in an educational institution such as university, leadership deserves to be independent, while Sengeôs five disciplines show that leadership has to be embedded onto each discipline.

There were many literatures written on the theme of measuring Learning Organization application. Sari (2012) conducted a research on Learning Organization Application in PT XL AXIATA, using qualitative methods. There are others as well that were conducted on the education industry using quantitative approach such as Navehebrahim \& Badakhshan (2013) and Veisi (2010). Quantitative measurement tools for learning in higher education institutions, however, are lacking. As seen in the said literatures, most researchers utilized widely used questionnaire constructed for organizations in general, and then modified the questionnaire to fit their need.

\section{MeThods And FINDINGS}

This research was conducted on two different approaches in order that it will provide a broader view of learning organization in the Faculty of Economics by complementing each other. Quantitative approach was conducted first, providing a descriptive study of learning at the surface level of the faculty. The qualitative approach was conducted to provide many explanations about what emerged on the surface and how it came to emerge. Then, both approaches were combined, providing a whole image of the faculty as a learning organization.

\section{A. Faculty of Economics as a Learning Organization (Quantitative)}

The descriptive study of Faculty of Economics as a learning organization was conducted by collecting questionnaires. The questionnaire used in this approach was based on Neefeôs Organizational Learning Questionnaire (2001). She based her questionnaire on Learning Organization Survey developed by Goh and Richards and modified the said questionnaire for university use. The population for this study was academic and administrative staffs of Faculty of Economics $(\mathrm{N}=103)$. From the population, a sample size was taken based on Harry Kingô nomogram $(n=34)$. The sampling method was the stratified random sampling. The strata consist of academic staffs and administrative staffs. The questionnaire for this study consisted of 31 items that were divided into 6 sub-systems of learning organization, which are Leadership, System Thinking, Mission/Vision Statement, Employee Skills and Capabilities, Team Work and Team Learning, and Organizational Culture. A five-point, Likert-type Scale (1-5) was used to indicate the degree of agreement toward the statements. To describe the findings, Overall Mean Score (OMS) was used. Cronbach Alpha of the questionnaire scored 0.926 , which was greater than 0.70 ; thus, it can be said reliable. For the OMS itself, class intervals will be used to explain the degree of agreement of the respondents toward the statements. The class intervals are as such: 1.00-1.80 (Highly Disagree), 1.81-2.60 (Disagree), 2.61-3.40 (Neutral), 3.414.20 (Agree), and 4.21-5.00 (Highly Agree).

According to the demographic data, the majority of the respondents are between 36-40 years old with a total of 8 persons $(23.5 \%)$. In term of the sex of the respondents, we can see that the majority are males with a total of 20 persons $(58.8 \%)$. Most of the staff have worked for the University for 21-25 years (10 persons that occupy $58.8 \%$ of total) and the same goes for the duration of work in the Faculty of Economies (10 persons that occupy $29.4 \%$ of the total). Respondents were divided into 2 categories based on the work types, which are; administrative and academic staff. The respondents consisted mostly of academic staff, totaling 26 persons $(23.5 \%)$. Lastly, the respondents are mostly studying at the graduate degree program (20 persons that occupy $58.8 \%$ of the total), as stated by the state that in order for one to be permitted to teach, one has to possess a graduate level education.

The result of the descriptive study itself can be observed as follows: 


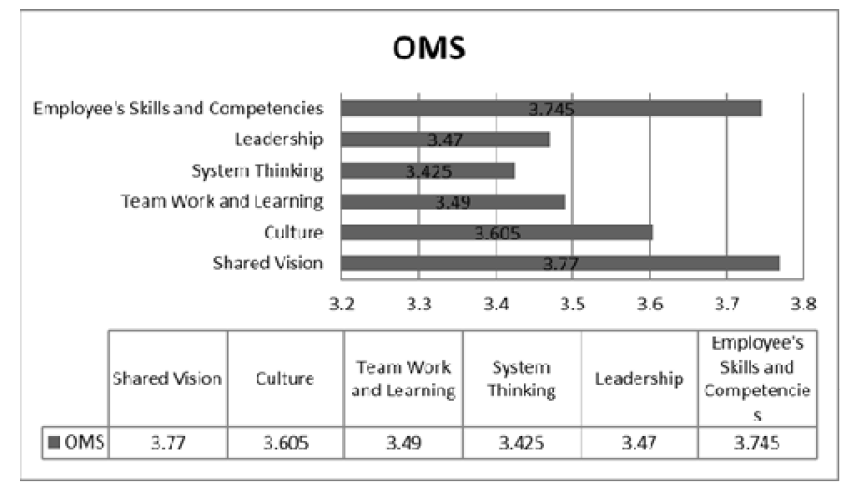

Fig. 1. . Overall Mean Score

From the figure, we can compare the data measurement with the class interval. Thus, the data shows that in all of the six sub-systems, the respondents agree that the faculty of economics is a learning organization, based on Neefeâs 6 subsystems. Here are figures of each subsystem:

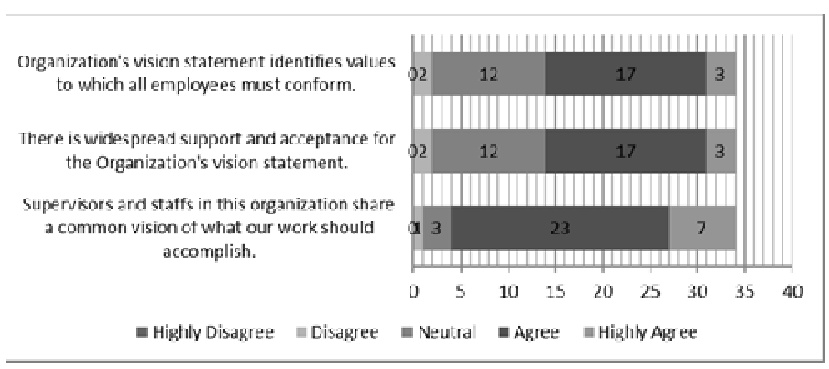

Fig. 2. Shared Vision/Mission

According to the overall mean score for the sub-system of shared vision/mission (3.77), it can be argued that the respondents agree that Shared Vision exists, promoting learning to exist in the Faculty of Economics. This finding reflects that perception of the respondents toward shared vision and its ability to promote learning is positive.

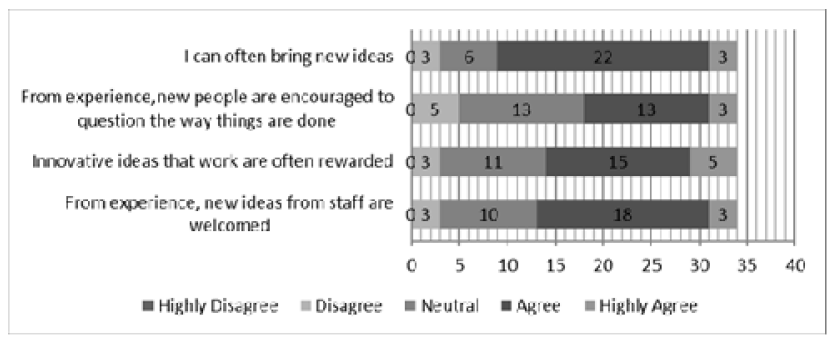

Fig. 3. Organizational Culture

According to the overall mean score of the subsystem of organizational culture (3.605), it can be argued that the respondents agree that the organizational culture that promotes learning exists in the Faculty of Economics. This finding reflects that the perception of the respondents toward organizational culture and its ability to promote learning is positive.

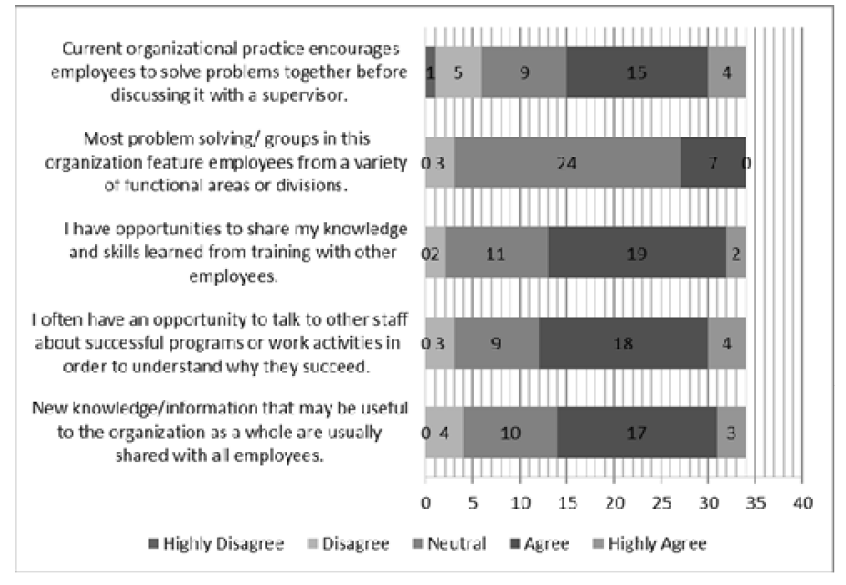

Fig. 4. Team Work and Team Learning

According to the overall mean score of the subsystem of team work and team learning (3.49), it can be argued that the respondents agree that team work \& team learning that promote learning exists in Faculty of Economics. This finding reflects that the perception of the respondents toward team work \& team learning and their ability to promote learning is positive.

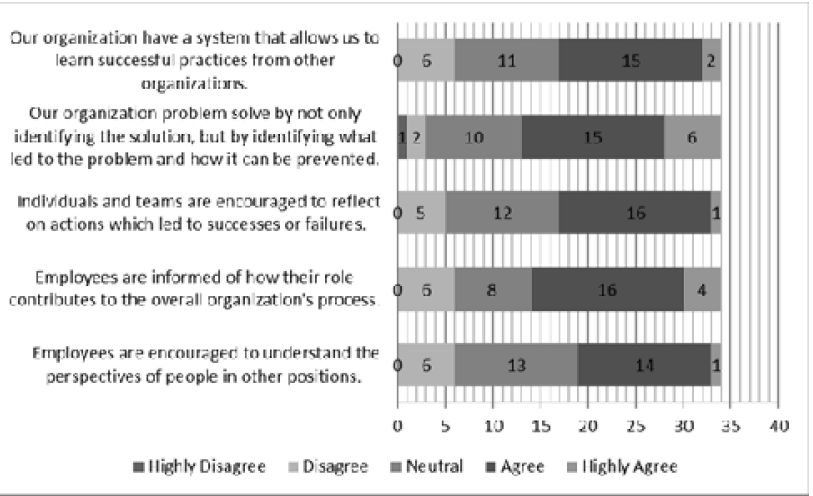

Fig. 5. System Thinking

According to the overall mean score of the subsystem of system thinking (3.425), it can be argued that the system thinking exists in the Faculty of Economics and it promotes learning. This finding reflects that the perception of the respondents toward the system thinking and its ability to promote learning is positive. 


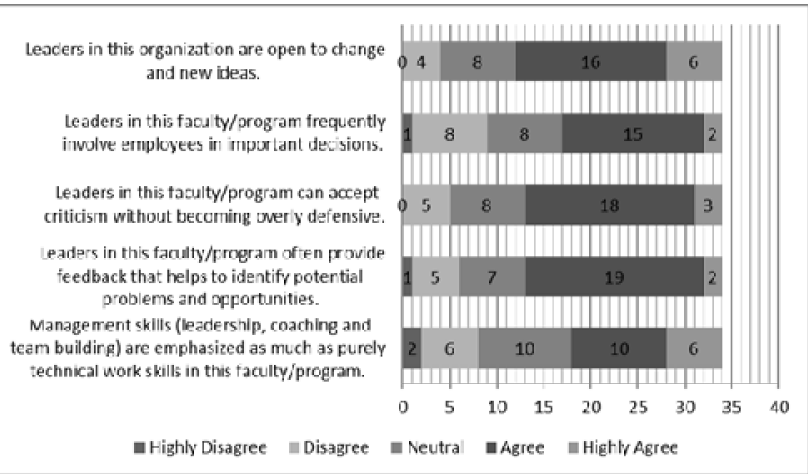

Fig. 6. Leadership

According to the overall mean score of the subsystem of leadership (3.47), it can be argued that the respondents agree that leadership that promotes learning exists in the Faculty of Economics. This finding reflects that the perception of the respondents toward leadership and its ability to promote learning is positive.

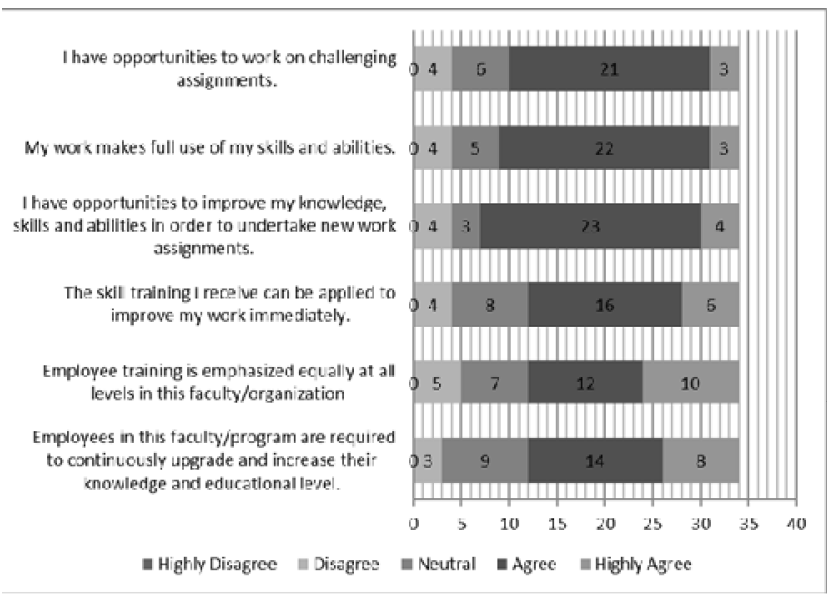

Fig. 7. Fig. 7.Employeeôs Skills \& Competencies

According to the overall mean score of the subsystem of employeeôs skills and competencies (3.475), it can be argued that the respondents agree that employeeôs skills \& capabilities that support learning exist in the Faculty of Economics. This finding reflects that the perception of the respondents toward employeeôs skills \& capabilities and their ability to promote learning is positive.

Hence from the quantitative findings described above, it may be concluded that faculty of economics is a learning organization based on perception of the faculty members. The findings shows perception on the surface level and thus need to be complemented with deeper understanding

\section{B. Faculty of Economics as a Learning Organization (Qualitative)}

The qualitative study of Faculty of Economics as a learning organization was conducted by initially performing semi-structured interviews. The interviews were guided by an interview guideline which the researcher constructed based on Sengeôs five disciplines (1990), namely: System Thinking, Mental Models, Shared Vision, Personal Mastery, and Team Learning. The sampling method used is judgmental sampling method, based on the researcherôs judgment. The sample consisted of six academic staffs of the faculty. All of the respondents have been in the university, specifically in the Faculty of Economics for at least 8 years. Two were females and four of them were males. Two of the six served the faculty in structural positions. The analysis was based on Miles and Hubermanôs three current flows of activity in the data analysis (1994). The researcher interpreted the activity and constructed three analysis steps, started with t0 table which contains a summary of the respondentsôresponses toward each question. Then, t1 table was constructed, containing generalization of the response of each question. The last one was $\mathrm{t} 2$ table which contained generalization of themes and responses, resulting in general theme for each discipline. The result is then displayed as follows:

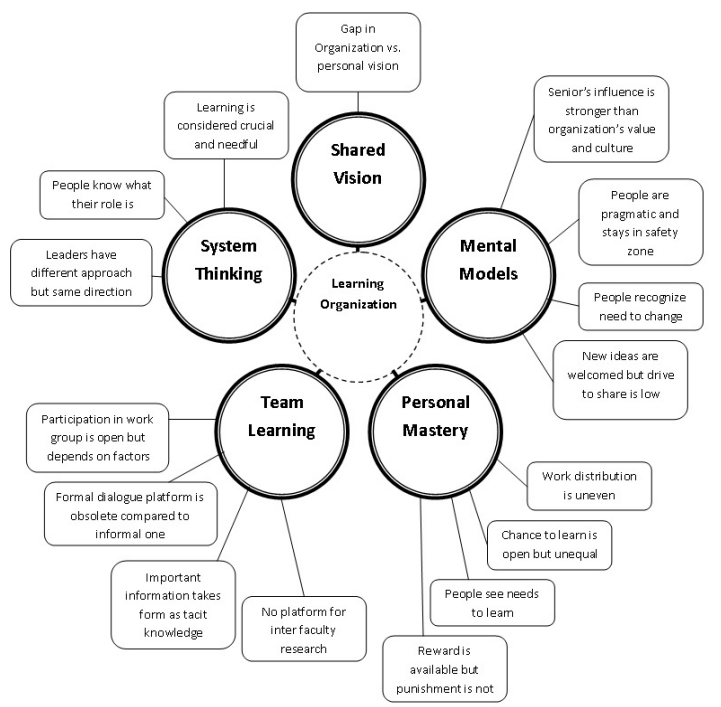

Fig. 8. Learning Organization Characteristics in the Faculty of Economics

After the figure was created, we can observe that in a qualitative approach, there are findings in the deeper level of perception. Interviews enabled the respondents to freely explain their perspective, providing richer information. From the figure, we can see that of the entire general theme in each discipline, not all of them actually supports learning. Each theme provides positive or negative magnitude toward learning. The explanations for findings are as follows: 


\section{Shared Vision}

The finding shows that there is a gap between organizational vs. personal visions in the Faculty. In the Faculty of Economics, from what were found in the semi structured interviews, it seems that almost all of the respondents had no idea about the vision and mission of both the university and the faculty. In term of the universityôs vision, it might be acceptable since the academic staff usually work under the faculty and do not have much interaction with the university, except for those who are holding certain positions. The facultyôs vision and mission are derived from those of the universityô, and in the Faculty the vision and mission are translated into a set of goals. The academic staff knows about the goals, but they do not know about the vision. The researcher tried to ask the respondents, and almost all of them said that they did not memorize it and tried to explain what kind of direction they have according to their interpretation. Instead of mentioning any value of the vision and mission, most of them mentioned the goals and universityôs principle which were set around two years ago. The researcher assumes that this phenomenon happens because the vision and mission statements are considered far away in the future and are unrelated with the daily operation. The reason why most respondents recognize the principle might be that the principle is new and was created during their employment, socialized to every staff, and easy to remember. This discipline displays negative magnitude toward learning because learning is enforced by the shared vision only if the organization members adopt the organizationôs vision.

\section{Mental Models}

The findings show that senior faculty members have a stronger influence on new recruits, compared to those of organizationôs value and norms. Not only that, the interview also reveals that people tend to be pragmatic and stay in a safety zone. But lately, people realize the need to change their behavior and mental models. The interview also shows that new ideas are welcomed, but the drive to share is low among the faculty members. Mental models in the Faculty of Economics are not only individual ways of thinking as a part of the organization, but instead it is a culture that is accepted by the majority of the faculty members and rapidly absorbed by new recruits. This might be caused by the facts that people mingle with each other in high intensity so that they may influence one another, while the Faculty didnô reinforce its value and norm as effectively. This also may be the reason why most of the faculty members are pragmatic and tend to stay in the safety zone. From the interviews, the researcher found that people in the Faculty of Economics had certain sets of expectations. But during their employment, they went through a change of heart because of certain obstacles. These obstacles might take many forms, and not everyone went through this phase, but only people who did change their whole perspective. One of the faculty members witnessed her family falling apart and the children going astray during her work as an academic adviser, leading her to rethink of her priority. While the other had an idealism to help Catholic institution to develop, the organization failed to aid this, leading to disappointment. During the last few years, many of the academic staffs built network outside the university and/or came back from their study abroad, bringing new ideas and slowly starting to change the way of thinking in the faculty. These people are small in numbers, but because they consistently encourage the new way of thinking, it has started to affect other faculty members who were pragmatic. The last indicator of this study revealed in the interview was ideas. The researcher found that ideas were encouraged, but most of the faculty members kept the idea to themselves. Exposing ideas to the leaders will lead to brainstorm and need assessments on whether the idea can or need to be realized or not. If the idea is accepted, the person who contributes the idea will usually be the one who will be assigned to realize the idea. Several people see this positively since they can actualize themselves and contribute to the faculty. Others, on the contrary, view this as an increase of work for them, with already unbalanced workload, which is unwanted. This is one of the reasons why people keep the idea to themselves.

\section{Personal Mastery}

The findings show that work distribution is uneven, not only between the tasks components, but also between peers. This is triggered by the fact that academic staffs have to fulfill the main responsibilities imposed by the government, the Tridharma (lecturing, researching, and community service), while the faculty demands the academic staffs to also work on supporting tasks. Lecturing is especially high in term of work load because of the high ratio between lecturers available and the students. Other time-occupying tasks are the supporting tasks. Different from lecturing, a supporting task in the Faculty is a bit unique since people who fail to fulfill the facultyôs expectation on their supporting tasks will be taken out of the pool, thus limiting the talent choice for the supporting tasks. This creates dilemmas among the leaders because this has led to heavy workload on the supporting tasks among certain people but not among the others. This is bad since people who fail will have the disadvantage of having a smaller chance to join any working groups. Supporting tasks are considered time consuming because they have little points compared to those of Tridharma in term of academic staffó evaluation. Research and community service, on the other hand, are relative to the person. In addition, people realize the needs to learn as something essential for them. The reason for the eagerness to learn, however, can be divided into two. The first reason why faculty members think that learning is important is that they perceive learning beneficial for them. For the academic staff, a higher degree means an access to a higher academic career level. It also helps them in their tasks. Meanwhile, for the administrative staffs, higher education means a higher chance to improve their living since people with an academic degree have better pay than those who are high school graduates. Training is seen as an aid to their daily tasks. The second reason for the faculty to perceive learning as 
crucial is that it is administrative in nature. To reach a good accreditation, a faculty has to have a certain number of publications, a certain number of Doctors, et cetera. The faculty believes that a higher degree for the academic staff is equivalent to a high rate of research, even though the relationship is yet to be proved. Although the eagerness to learn is high, chances provided by the faculty to learn is open to everyone, but it is unequal. The leaders expressed that even though anyone can propose to be funded during their study, there are determinant factors that are known only to the decision makers, and unopened to public (faculty members in general). According to one of the leaders, the factors are, among others, but not limited to: commitments shown toward the organization, motivation to study, behavior in the Faculty, historical record, strategic planning (on what discipline needed by the faculty), and quota (budget constraint and including a number of academic staff currently studying). From what the respondent comprehend, the task itself serves as a great determining factor. People with a high rate of success in their tasks and outstanding performances will be favored due to their historical records. For the administrative staffs, chances are open as well, even though the majority of the administrative staffs are not eager to be funded due to the contract that will be put legal binding on them upon completion of study. For training and courses there is no problem since there is budget to accommodate them and they do not need too much time. Lastly, reward is available to encourage learning, through tasks, but punishment is absent.

\section{Team Learning}

The findings show that the formal dialogue platform in the faculty is obsolete compared to the informal one. In a learning organization, dialogue has to be encouraged by the organization. A way to encourage the said discussion is to provide a medium or platform for every faculty member to mingle and create a learning atmosphere where people are comfortable to speak out their thoughts. In the Faculty of Economics, only the academic staffs are given such a platform formally, depending on the task. For the academic staffs, however, a platform is provided. Though along its journey the platform serves many functions from a scientific to socialized meeting, the platform was meant for knowledge sharing. Even though it has resulted in several proposals and grants, the real dialogue that sparks an idea takes place in informal small groups between academic staffs and those with the same interests or aspirations. It is limited, for sure, since not every group has the same view on the urgency of learning. But it is a sign of self-initiated learning among the faculty members, which is good. Also, there is no platform for inter-faculty research. Inter-faculty research takes place based on the personal relation between individuals. The leaders consider such a platform unnecessary since research is based heavily on personal preferences. Besides research, another task that involves people from the possible different units (limited to units because each faculty has its own authority) usually only involves a certain group of people. Membership of this group was not expressed by any of the respondents, and thus the criteria are unknown. But according to one respondent, the leaders handpick people who will be in the team, but the considerations remain unopened. Some of the respondents expressed that failure in previous group membership will lead to a smaller chance of being picked for the next working team. Since the working group usually involves a certain group of people, usually the group is always same. In the work process they work on, the formal documentation exists but it cannot be referred to next time the same process/problem occurs. This is due to knowledge relating to the process that belongs solely to the group member in the form of tacit knowledge and it is not documented properly. People who are new to the group or newly in charge have to ask the people joining earlier if such a process/problem ever occurs again. It is unclear how the faculty will respond if one day the key person is no longer in the university and the process/problem occurs. It is against learning organization principle where information should be able to be accessed by all faculty members whenever they need it (Marquardt, 2002). The information can be shared with other faculty members, but there is a tendency of other faculty members who do not ask for information necessary for their current work. The researcher thinks that it might be another norm that is widely accepted in the university that people who have no business does not need to know. Whether they will need to know in the future is another story.

\section{System Thinking}

The findings show that learning is considered crucial and needful by the faculty members and the leaders. People inside the faculty know their role in the faculty. The leaders have a different approach but, generally, the course stays the same. We can see that the respondents agree that learning is important because not only does it affect themselves, but also the students, their future research and community service, and the faculty, both administratively and academically. Most respondents can see how they play an important role in the organization. This precious perspective cannot be forced by the organization, but it has to be discovered. The academic staffs discover this mostly by themselves or by their seniorô guidance. There is no mentoring department for the academic staff, one to another. But solidarity as an academic staff drives the senior to guide the junior, or at least as observed by the researcher. This knowledge of a role one possesses in the organization is indeed valuable, but it is useless without proper leadership. From what the researcher observed, the overall direction of the faculty during the change of dean is relatively the same, but only a different approach or method. It is acceptable since a leadership style differs one to another person. The dean has to provide direction and clear guidance on what the faculty tries to achieve. Even though as explained in the shared vision section most of the respondents have no idea about the vision, at least they still stick to the principle and goals set by the faculty. The dean as the leader of the faculty has to make sure those principles and goals that the faculty members hold on to will be utilized to move the 
faculty to the direction intended. To conclude, system thinking shows acceptable magnitude that affects learning of the Faculty of Economics.

\section{Outcome Space}

The findings in quantitative and qualitative approaches show similar but different impacts toward learning in the organization. The magnitude of each discipline/sub-system is then assigned and displayed to provide a broader view based on the relationship.

\begin{tabular}{c|ccc}
\hline \multicolumn{2}{c}{ Quantitative } & & \multicolumn{2}{c}{ Qualitative } \\
\hline Subsystem & Magnitude & Magnitude & Discipline \\
Shared Vision & +++ & - & Shared Vision \\
Culture & ++ & - & Mental Models \\
\hline $\begin{array}{c}\text { Employeeô Skills and } \\
\text { Capabitilies }\end{array}$ & +++ & + & Personal Mastery \\
Team Work \& Learning & ++ & + & Team Learning \\
System Thinking & + & + & System Thinking \\
\hline Leadership & ++ & & \\
\hline Fig. Q. Quantitative vs. Qualitative (Outcome Space) & \\
\hline
\end{tabular}

Fig. 9. Quantitative vs. Qualitative (Outcome Space)

Magnitude is shown as positive (+) or negative (-). For the quantitative, the magnitudes are amplified to highlight disparity in scores between the sub-systems as shown in Figure 1. According to the class intervals, all of the subsystems in the quantitative method would be grouped in the same class as ñAGREEò. But staying faithful to the class interval will lead to failure in capturing the phenomenon. The more the (+) signs, the more positive the sub-system support toward learning. Assigning the magnitude was based on the researcherôs subjectivity to picture various degrees of support toward learning by each discipline/sub-system.

There was almost no previous research featuring such an outcome in the topic of Learning Organization, and even if one exists, it is in very few in numbers. The researcher based the model of qualitative on Sariôs (2012) that used a qualitative approach. However, as seen in Sari (2012), the researcher merely attempted to prove whether the organization was a learning organization or not. But in this study, the researcher found that describing how the sub-systems being perceived as a research object is very important. Sariố research was normative, and thus the researcher attempts to map each sub-systemô position in the negative and positive area to serve as a starting point for future studies to identify factors that burden the learning implementation in the organization. The positive (+) and negative (-) assignments in the outcome space indicate whether the sub-systems are still in an early stage or implemented stage.

As we can see in Figure 9, or Employeeôs Skill \& Competencies, Team Work \& Learning, and System Thinking, the differences are not very significant since all of them display positive influences toward learning. Shared vision and Culture show very different results in the comparison, whereas the quantitative method shows a highly positive result; meanwhile, the qualitative method shows relatively negative results. From the 6 sub-systems used in the quantitative approach, we have to note that some of the sub-systems are ignited by the organization, while the others are ignited by the individuals. While the sub-system of Shared Vision, Culture, and Leadership are arguably ignited by the organization or leadership, the Sub-systems of Employeeôs Skill \& Competencies, Team Work \& Learning, and System Thinking are generally ignited by the individuals, with the aid of leadership. The extreme differences in our case, however, take place in those three sub-systems. Even though the Leadership sub-system has no direct equivalent, it is embedded in every discipline in the qualitative approach. Since it shows relatively different results, the researcher concludes that leadership has to be investigated as well.

Shared Vision shows different magnitude in both approaches. While the quantitative approach shows that it scores highly positive, the qualitative approach says otherwise. We can see from the question items of this sub-system that it indeed attempted to explain that vision defines values, shows what the work should achieve, and whether or not the vision is supported. However, it should be noted that the questionnaire lacks one very important question. It didnâ show how deep the staffôs knowledge of vision and whether the respondents adopt it as a personal vision or not. The vision might be translated into a set of target (achievements) and values (norms), but being translated does not mean all of faculty members truly understand. The researcher suspects that the main problem here is communication. The faculty members feel no urgency to learn about the direction, and moreover to adopt it. The vision statement remains as some set of words that can be shown to an assessor when there is any assessment for administrative purpose. It is as if the vision is only important for people with positions, while the staffs do not need the direction.

Next is the organizational culture sub-system. Analysing the questionnaire items again, we could find that the questionnaire tried to investigate rewards and punishment, how faculty reacted to new idea proposed by staffs, and encouragement toward being critical. When given the questionnaire, the respondents could answer quickly, but there are certain aspects on the statement that the questionnaire failed to explain. Rewards and punishment could be explained, although it was not as deep as the interview. New ideas are described as welcomed, but their execution depend on the leaders and the leaders tend to assign the execution of new ideas to the person who proposed the idea. With such tendency, people who have an idea will tend to keep the idea to themselves, since workload is already high and contributing an idea brings more trouble. Other than that, the questionnaire fails to explain how people tend to think in the organization. It is not because the questionnaire is obsolete, but because a way of thinking is not something to be asked with five levels of answer. By conducting interviews, the researcher has succeeded in generalizing peopleôs way of thinking inside the facility. The pragmatic and simple way of thinking, as well as risk avoiding behaviour is becoming a culture. It is not a 
culture intended by the organization. Ideally, the organization creates the culture, based on values and norms. But in the Faculty of Economics, culture and values created by the organization are not strong enough that the widely accepted culture and value are the ones created by the faculty membersô disappointment or changes in the way of thinking during their employment. However, it has changed lately. It can be seen from how the respondents remember the universityó principle which explains virtues in the university and how the pragmatic way of thinking is shifting into changes in oriented views. The interview scored negative because at the moment the interviews being conducted, that was the condition. Even though a change is expected in the near future, it will move slowly inside the faculty. As a shift of mind is occurring between the young people, people who network outside the university, and leaders that realize the need for changes, there are also people who are not ready to change. The speed of a fleet is the speed of the slowest ship, and so it happens in an organization as well.

Employeeô Skills \& Competencies score higher in the quantitative method; maybe because the questionnaire didnô explain that even though the chance to self enhance is open to everyone, it is not equal. There are factors that determine whether or not an employee will be able to be funded. One of them is historical track. While the leaders make the final decision, it is the staffs that determine whether they are qualified or not. The staffôs lack of commitment, lack of enthusiasm, and several failures in the past will put such a candidate on the last option. Unfair, most of people would think. But funding on a study is a big stake an organization has to decide. The decision makers are rational to put certain consideration, as long as it is objective. Most items in the questionnaire only indicate the existence of such practice, while deeper, we can find that there are other conditions that follow the practical execution. In addition, each person perceives the statement item differently. For one respondent, his/her work is considered to fully utilize his/her skills and capacity, while for another, it is not.

The next sub-system in question is team work \& learning. The quantitative approach scores slightly higher than those of the quantitative. The most important trait in this sub-system is sharing. Knowledge sharing is the heart of team work \& learning, and thus dialogue is important. From the questionnaire, we can see that people think they can share knowledge, successful practices, and basically any useful information. In the interview process, we can see that such a platform is provided. A media for brainstorming. Not limited to a proposal discussion, knowledge sharing, or even just talks and interactions with each other. But again, from the interview we can see that the media didnô work quite as expected. The platform is provided, schedule cleared, place provided in the faculty, but one more crucial factor does not fulfil the expectation, which is, the human beings. Either the academic staff is too scared to make criticism, has no interest in such dialogues, thinks that it is time wasting, and too different discipline backgrounds, or else. The interview provides a small number of details in this matter. The researcher believes that everyone in the organization, especially the academic staff, has a different perception of what a scholar should be, on their work, on their daily work, on their mind. The discussion happens, still, but not in the formal platform provided. Instead, it takes place in small informal groups. The other important thing pointed by the questionnaire is how closely every group member can work. In the researcherôs opinion, this might score high because there are not many problems in the team work. This might be due to the membership of the group. As explained before, in the Faculty of Economics, everyone is given tasks, whether individual or group tasks. Success in these tasks will earn trust from leaders, thus granting the possibility of future membership in the working group. This is not necessarily positive or negative, because it depends on the perspective of the person. For one person, membership in a group is a benefit because they enjoy more work, while for another person, it is undesirable because it occupies the time they can use to conduct a research or write a book instead. The interview also discovered certain tacit knowledge that belongs to some groups of people that is not shared with public unless it is necessary. This put people with tacit knowledge on certain positions, while people without such knowledge will have less chances and have to rely on people with tacit knowledge since the organizationôs documentation is not helpful. Another form of team working takes form in inter-faculty research. The questionnaire didnâ explain that either. But from the interview we can see that it happens, but in a very limited rate since inter-faculty research is limited to the personal relationship among the researchers, since the platform for such function does not exist.

Next is the system thinking. In this sub-system, learning at the level of organization is explained. This sub-system scores quite high on the quantitative approach. It is relatively the same as those in the quantitative approach so the researcher concludes that there is not much to explain since both methods agree that the system learning in the faculty supports the learning positively but not with very high rate.

The last one is Leadership, which affects all disciplines according to Senge. In this part, leadership has no counterpart in the qualitative approach since Senge thinks that leadership has to be embedded into 5 disciplines explained previously, while Neefe thinks that in the educational institution such as University/College, it deserves a place of its own. Leadership in the Faculty of Economies itself is divided into many levels. University level leadership plays a big role since every policy in a faculty is derived from the universityô policy. In the faculty, faculty level leadership has a big scope since it houses three departments. Leadership at this level is generally considered stable. But on the department level, it is a different story since several years later, a change of leader takes place quite often. The type of leader will affect every other subsystem/discipline. There are leaders who are future oriented, but there are leaders who are operational oriented. The researcher fails to dig deeper into this topic. But the researcher notices that the failure of several sub-systems and disciplines 
has to be attributed to this sub-system. Leadership has to provide mental models for every faculty member to follow. Thus, leaderôs failure to be a role model will result in loss of learning, as explained in the previous section. Leaders also determine whether faculty members will adopt the organizationôs vision or not. The researcher concludes that even though an individual in the organization is a big determinant factor for learning to take place, leadership is another big determining factor that might be able to influence the faculty membersôtendency to learn.

\section{Conclusion And Suggestions}

Taking a conclusion of the analysis between two approaches, the researcher founds that Senge (1990) provides a philosophical guidance for an organization to be a learning organization, regardless of the industry. But Educational institution is a very unique organization that tends to be traditional; thus, the researcher agrees with Neefeô leadership sub-system because in an organization with a strong hierarchical order, leadership is a determinant factor that will affect the other disciplines/subsystems.

Following close observations, there are two triggers that determine the magnitude of each sub-system toward learning in the Faculty. Those triggers are the individuals and the leadership. It is true that learning starts in the smallest component of an organization, which is individual learning (Marquardt, 2002). But while some of the subsystems are ignited by the individuals, such as personal mastery, all of the sub-system is not fully ignited by only one party. Instead, it is ignited by both parties, but to a certain degree. Thus, some sub-system individuals dominate, while another sub-system leadership dominates. However, an individual is also influenced by the leadership as well.

In the analysis, the researcher sees that leadership is a crucial factor that fails to perform perfectly, due to many factors. This is unfortunate since leadership can bring this organization to thrive even further if used properly. It is expected that this research serves as a reflection for the leaders and future leaders of the Faculty of Economics of how the staffs perceive the organization, leadership, themselves, and the students as an environment. In a faculty such as the Faculty of Economics, a decision making process is not a process undertaken by merely a leader. Because of the collegial leadership, decision making process is not to be done quickly. It is because of the organizational structure that involves many people in the decision making positions, and thus every decision made has to be considered as a part of long term process which has to be assured of its sustainability. They have to also make sure that the decision will be carried on by their successor. This is why a leader in the Faculty of Economics has to take many accounts into consideration in the decision making, without taking too much time that will delay any process.

Learning from both approaches, the researcher concludes that the Faculty of Economics is a learning organization, but only in the early stage. Even though not every sub-system shows a positive magnitude toward the statement, the researcher sees, in accordance with the quantitative approach, that learning takes place. Even if now it is not strong yet, the researcher believes that in the near future, learning will be more general in the Faculty of Economics. The differences and similarities of both approaches show that things are not as visible on the surface. Things are not as they seem due to the complexity of the organization where many factors play important roles.

During the interviews, the researcher found that many respondents went through an obstacle or several of them, causing changes of view of their employment. These obstacles are not the full responsibility of the organization; sometimes such obstacles are out of control of both parties. But future research may be conducted to find what obstacles play the big part in changing the respondentôs way of thinking, since it can explain further how the obstacles take effect before and after they take existence. However, the fact that the university in this case study is a university draws a clear line that differentiates this research from Sarió (2012). Also, the fact that the university is located in Indonesia and a Catholic University also plays a role that makes this research different from Veisi (2010) and Naverbrahim\& Badakhshan (2013) who conducted studies in a university in Iran. Thus, this study is not to generalize universities of faculties of economics in Indonesia, nor Jakarta.

Limitations of this study also play an important role in this research. For future research, this research can also be improved by conducting such research in different faculties of the university, or even conducting a massive scale research on the whole university, both the faculties and the bureaus/centres/institute/units. The sampling method might be changed into Slovinôs formula (in Sekaran, 2003) or any other methods that draw over $50 \%$ of the population, to capture more comprehensive and deeper phenomena regarding a Learning Organization. If any future researcher wishes to improve this research, the sampling size is one thing to be improved since the sample size in this study is considered too small. This research can serve as a foundation if any other researchers wish to construct a questionnaire to measure the learning organization in Indonesian Universities, since the modified questionnaire used in this research didnâ capture the whole image of the Indonesian higher education institutions. A construct of future questionnaire should be made differently for private universities and state universities. The size of a university also plays an important role in determining variables the measurement tools tries to capture. Note that in Indonesia, higher education institutions are not only universities but there are also academy, institute, polytechnic, et cetera. All of these have to be taken into account in constructing new measurement tools in the future to ensure reliability and validity.

This research has thus reached a conclusion, that the Faculty of Economics is a learning organization, but with a note that many things still have to be improved if the Faculty of Economics wishes to stay competitive in a changing world 
as today. The complexity of the practices, norms, and values inside the organization are what make the Faculty of Economics stand out from other similar institutions. The said complexity can serve as a cornerstone for improvement, but it can also act as an obstacle, depending on the leadership.

\section{References}

[1] K.M. Kapp, ñTransforming Your Manufacturing Organization Into a Learning Organizationò. Hospital Material Management Quarterly, May 1999, Vol.20, Issues 4, Pages 46-55

[2] C. Argyris, and D. Schön, Organizational learning II: Theory, method and practice, Reading: Mass: Addison Wesley, 1996.

[3] P.M. Senge, The Fifth Discipline: The Art and Practice of the Learning Organization. New York: Doubleday/Currency, 1990.

[4] M.J. Marquardt, Building the Learning Organization: Mastering the Five Elements for Corporate Learning. Palo Alto: Davies-Black Press, 2002.
[5] A.P. De Geus, "Planning as Learning." Harvard Business Review. March 1988.

[6] D.O. Neefe, Comparing levels of organizational learning maturity of colleges and university participating in traditional and non-traditional (Academic Quality Improvement Project) Accreditation Processes, University of Wisconsin Ï Stout Menomonie, WI. 2001, 54-75.

[7] A. Navehebrahim, and A. Badakhshan, "An Evaluation of The University as a Learning Organization." Australian Journal of Basic and Applied Sciences 7 (7), 2013, pp. 148-54.

[8] F.P. Sari, Penerapan Learning Organization Di PT XL AXIATA TBK Thesis. Universitas Indonesia, 2012.

[9] U. Sekaran, "Research Method for Business: A Skill Building Approach." $4^{\text {th }}$ ed. New York: John Wiley \& Sons, 2003.

[10] H. Veisi, "Organizational Learning in the Higher Education Institutions (A Case Study of Agricultural and Natural Recourses Campus of University of Tehran)." International Online Journal of Educational Sciences 2.1, 2010, pp. 23-36

[11] M.B. Miles, and A.M. Huberman, AM. Qualitative Data Analysis: An Expanded Sourcebook. Thousand Oaks: Sage Publications, 1994. 